\title{
Integration of Energy Storage Connection with Combustion Chamber of Diesel Engine to Reduce NOx Emission
}

\author{
Dion Arman Lilipaly ${ }^{1}$, Karsten Wehner ${ }^{2}$, Steffen Loest ${ }^{3}$
}

\begin{abstract}
NOx is one of the chemical compound that contained in the acid rain. It is not only bad for human health but it also effected the environment for instances lake acidification. To overcome that problem, IMO made a regulation that controls the NOx emission that forced the shipping company to reduce their NOx pollution in certain areas. Hence, a new technology or method are needed to comply with those IMO Tier regulations. A new idea has been proposed that could reduce the combustion temperature by integrating an external chamber connected with the combustion chamber as a temporary energy storage. This method is implementing the pressure-temperature law, where the pressure is reduced by expanding the volume that resulted a temperature decreased. The aims of this study were to make a combustion model simulation and technical drawings design of the external chamber. The simulation model involves an analysis of how the temporary energy stored effected the combustion temperature and calculating the pipeline losses. The results showed that by installing the external chamber, the combustion temperature was reduced significantly by $6.15 \%$ for the burn zone and $17.8 \%$ for the unburn zone. Furthermore, a comparison of the pipeline heat loss showed that an insulated pipe saved $99.6 \%$ more heat energy than the uninsulated.
\end{abstract}

Keywords—design, external chamber, simulation.

\section{INTRODUCTION}

G lobal warming is a huge problem for all of the nation. Every country has its own way or policy to prevent the climate change to get worse, for instance the U.S has its own environmental protection agency and European Union has their Euro Standard. According to Mckinsey, the annual worldwide automotive growth from 2012 till 2020 is 6 percent. And most of them still used an internal combustion engine as their prime mover. Diesel engine is one of the IC engine that was very popular to used [1-3].

Diesel engine is a very common type of engine that used in many kind of industries, such as, transportation and power plant. High thermal efficiency and also durability are the reasons why they choose this internal combustion engine. Due to high compression that led to high temperature combustion resulted a chemical process that produce NOx emission. Furthermore, a short time of combustion led to incomplete combustion that resulted a soot particle which is very dangerous to human health and environment [4-5].

Dion Arman Lilipaly, Department of Marine Engineering, Institut Teknologi Sepuluh Nopember, Surabaya 60111, Indonesia, Email: dionlilipaly@gmail.com

Karsten Wehner, Hochschule Wismar University, Germany. Email: karsten.wehner@hs-wismar.de

Steffen Loest, Hochschule Wismar university, Germany, Email: steffen.loest@hs-wismar.de
Nitrogen Oxides (NOx) is a highly reactive gas, which consist of nitrogen and oxygen in a chemical bond. Commonly, NOx is resulted from a high temperature combustion. Nevertheless, there are 3 opportunities for NOx to form, thermal NOx, fuel NOx, and prompt NOx. Meanwhile, soot is a black carbon particle, which has a dimension of 2.5 micrometers that resulted from an incomplete combustion. According to environmental protection agency of the U.S, there are many ways to reduce those two pollutions [6-8].

In this research, a modification to the combustion chamber by adding an energy storage consist of a spring and additional chamber, will eventually reduce the peak pressure of the combustion and also increase the combustion time that led to the decrease of NOx and Soot emission. Hence, the additional chamber will be built and installed directly into the engine. However, there are still considerations in the energy storage especially, the volume and the spring dimension.

\section{METHODS}

Two zone combustion has been used to model the engine combustion. In two zone model, the environment inside the combustion chamber are assume consist of two zones, the burned zone and the unburned zone. The two zones are utilizing the thermodynamic (First Law of Thermodynamics) systems with energy and mass interactions between themselves and their common surroundings, the cylinder wall [1].

Burn and unburn zone combustion volume:

$V_{1}+V_{2}=V(\varphi)$ 
Burn and unburn mass fraction:

$m_{1}+m_{2}=m(\varphi)$
Burn and unburn zone pressure:

$p_{1}=p_{2}=p(\varphi)$

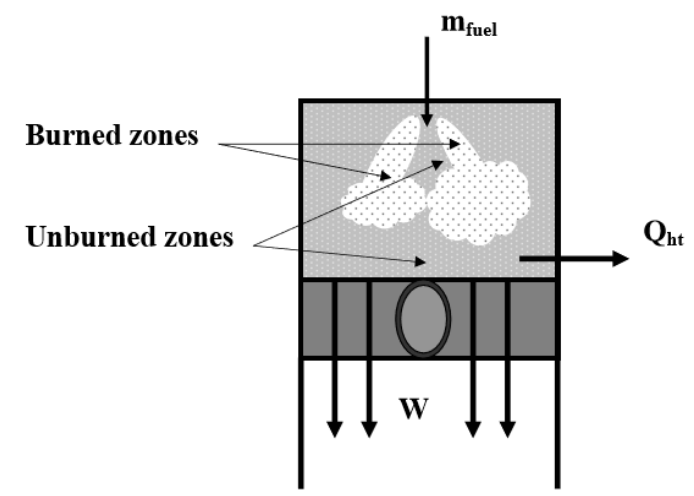

Figure. 1. Two Zone Combustion Model

Source: me.ud.edu

\section{A. Burn and unburn mass fraction}

Whilst the mass inside the cylinder is known, the fraction combustion chamber gasses can be made into burned and unburned masses. The initial condition of the instantaneous change in mass-fraction burned $\frac{d X_{b}}{d \varphi}$ is zero. Burn zone mass fraction:

$$
m_{1}(\varphi)=m_{1}(\varphi-1)+\frac{d x_{b}}{d \varphi}(\varphi) m(\varphi)
$$

\section{Unburn zone mass fraction:}

$$
m_{2}(\varphi)=m_{2}(\varphi-1)-\frac{d X_{b}}{d \varphi}(\varphi) m(\varphi)
$$

Instantaneous change in mass-fraction burned:

$$
X_{b}(\varphi)=1-\exp \left[-a\left(\frac{\varphi-\varphi s o c}{\Delta \varphi_{C D}}\right)^{k+1}\right]
$$

\section{B. Burn and unburn temperature}

The most common way to solve the burned and unburned temperature is by using the ideal gas assumption. The method can be used when the mass, volume, pressure and gas constant are known.

\section{Unburn zone temperature:}

$T_{2}(\varphi)=\left(\frac{p(\varphi) V(\varphi)}{m_{2}(\varphi) R_{2}}\right)-\frac{\left(\frac{m_{1}(\varphi) \cdot R_{1} \cdot B(\varphi) \cdot A^{*}}{m_{2}(\varphi) \cdot R_{2}}\right)}{\left(1+\left(\frac{m_{1} \cdot R_{1}}{m_{2 \cdot R_{2}}}\right)\right.}$

\section{Burn zone temperature:}

$T_{1}(\varphi)=\frac{p(\varphi) V_{1}(\varphi)}{m_{1}(\varphi) R_{1}}$

There is also another method that was proposed by Heider. There are considerations which lead to the following empirical method for the temperature difference between both of these zones.

\section{Heider Method:}

$T_{1}(\varphi)-T_{2}(\varphi)=B(\varphi) A^{*}$

For the function $\mathrm{B}(\varphi)$ is valid. Based on Woschni, $\mathrm{B}(\varphi)$ is function which leads the difference between the cylinder pressure $\mathrm{p}(\varphi)$ and the theoretical pressure $\mathrm{P} 0(\varphi)$ is utilized for the consideration of the influence of combustion and $A^{*}$ describes the temperature level in reaction zones as the start of combustion. $\mathrm{Cgl}$ for engines with 4-valve technology and central injection nozzle is 0.15 and for engines with 2-valve technology and a side injection nozzle is 0.07. $\mathrm{xgl}$ describes the global air-fuel ratio. $\lambda_{0}$ for small to the medium-sized diesel engine is 1.0 and large diesel engine is 1.03 .

\section{Woschni function:}

$B(\varphi)=1-\frac{\int_{\varphi s o c}^{\varphi}\left[p(\varphi)-p_{o}(\varphi)\right] m_{1} d \varphi}{\int_{\varphi S o c}^{\varphi E O C}\left[p(\varphi)-p_{o}(\varphi)\right] m_{1} d \varphi}$

Engine specific factor:

$A^{*}=A \frac{1.2+\left(\lambda_{g l}-1.2\right)^{C g l}}{2.2 \lambda_{0}}$

The amount of A can be determined from the table II.1 below. With $\lambda_{0}=\lambda_{\mathrm{gl}}$ and $A^{*}=$ constant . 
TABLE 1. ENGINE SPECIFIC FACTOR (A) VALUE

\begin{tabular}{cccccc}
\hline $\begin{array}{c}\text { Bore } \\
{[\mathrm{mm}]}\end{array}$ & $\begin{array}{c}\text { Stroke } \\
{[\mathrm{mm}]}\end{array}$ & Cycle & Comp.ratio & $\begin{array}{c}\text { Rated } \\
\text { speed }\end{array}$ & $\begin{array}{c}\text { A } \\
{[\mathrm{K}]}\end{array}$ \\
\hline 79.5 & 95.5 & 4 & 19.5 & 4000 & 1650 \\
128 & 142 & 4 & 16 & 2100 & 1740 \\
160 & 180 & 4 & 14 & 1500 & 1580 \\
480 & 600 & 4 & 14 & 450 & 1650 \\
580 & 1700 & 2 & 17 & 127 & 1655 \\
\hline
\end{tabular}

\section{Mechanical Work}

The mechanical work is the output energy from the piston that can be calculated while the pressure and cylinder volume changes are determined.

$\frac{d W}{d t}=-P \frac{d V}{d t}=-P \omega \frac{d V}{d \varphi}$

\section{Heat Transfer}

Heat transfer consist of conduction, convection and radiation. Sometimes the radiation (dQE/dt) is added to the convective heat transfer coefficient, although the maximal of (dQ $\alpha / d t)$ and (dQE/dt) actually appear shifted with reference to the crank angle.

$\frac{d Q_{w}}{d t}=\Sigma_{i} \alpha_{i} A_{i}\left(T_{w, i}-T_{g a s}\right)$

The cylinder liner consists of three different things. The cylinder head, piston and also the liner itself.

$A_{\text {liner }}=A_{\text {chamber }}+A_{\text {Piston }}+D \pi s(\varphi)$

\section{E. Heat Release}

Heat release is the energy that resulted from the combustion process in a form of heat. To calculate it, most diesel engine use double vibe function. This method divided the combustion period into two are, premixed area and mixed area.

$Q_{\text {ftotal }}=m_{\text {fuel }} \cdot N C V_{\text {fuel }}$

\section{F. Internal Energy}

The internal energy is the energy that related to the pressure, temperature, gas composition and the heat losses. When all of the parameters have been obtained, the internal energy can be determined.

$\frac{d U}{d t}=\frac{d Q_{w}}{d t}-\frac{d w}{d_{t}}+\frac{d Q_{f}}{d_{t}}+\left(H_{\text {in }}-H_{\text {out }}\right)$

To calculate how much volume and energy that the secondary chamber can store is depending on the engine specification.

TABLE 2.

ENGINE SPECIFICATION

\begin{tabular}{lll}
\hline Bore & 0.15 & M \\
Stroke & 0.18 & M \\
Number of Cylinder & 1 & \\
Compression Ratio & 12 & \\
Engine Speed & 1500 & RPM \\
\hline
\end{tabular}

\section{RESULT AND DISCUSSION}

\section{A. Engine Combustion Simulation}

There are several parameters that need to be measured in order to calculate the two-zone combustion model.
1) Parameters

The parameter that are needed for the calculation are the heat transfer coefficient, cylinder pressure, fuel and gas mass. All of those data are only for one load condition (1500 rpm) and each data have a value in each of 0.25 crank angle. 


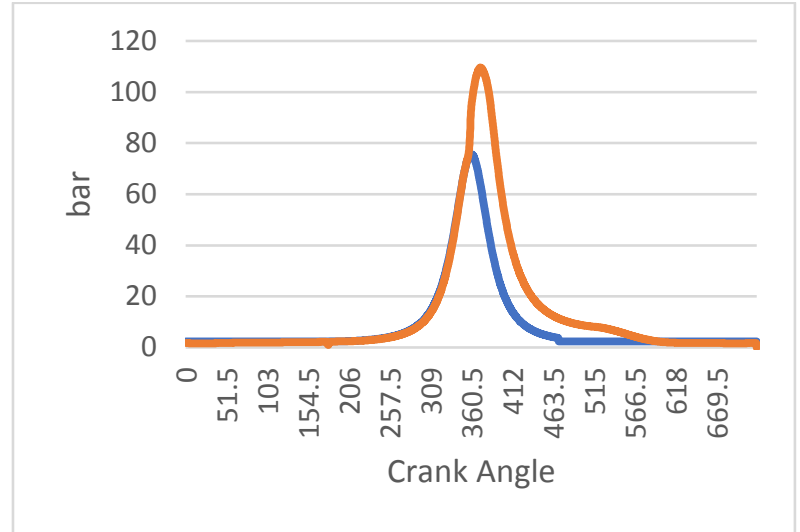

Figure. 2. Compression and Cylinder Pressure

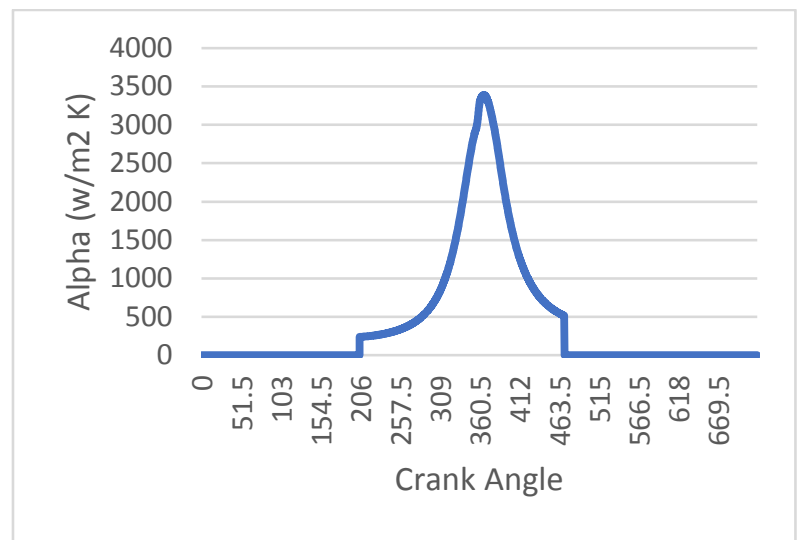

Figure. 3. Heat Transfer Coefficient

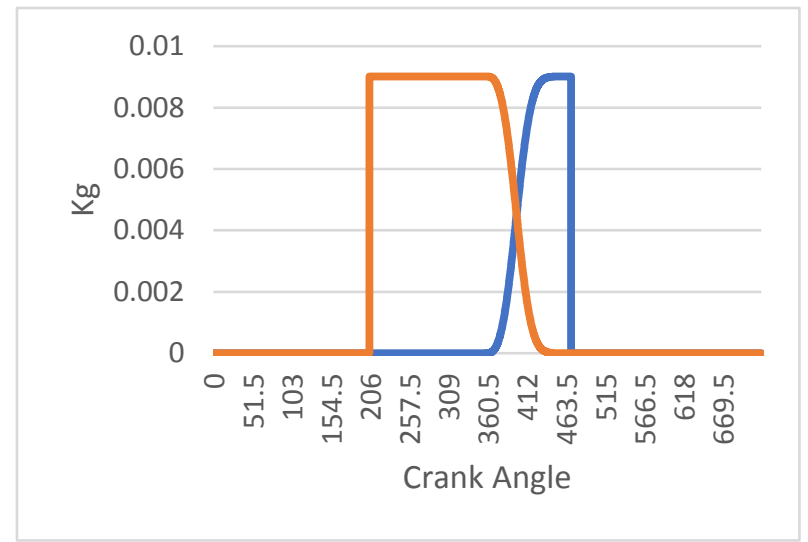

Figure. 4. Burn and unburn mass fraction

From the graph can be seen that the peak pressure of the combustion is 109.61 bar. The combustion starts at 352.25 CA and ends at 435.75 CA. Therefore, the peak pressure would have occurred around those two crank angles interval. The graph down below illustrates the heat transfer coefficient per crank angle.

The heat transfer coefficient began rising when the intake valve closed. That can happen due to the adiabatic process inside the combustion chamber. This coefficient is very important to calculate how much heat energy that were produced inside the combustion chamber. The bigger the alpha the higher the heat energy will be.

2) Combustion Temperature
The combustion is divided into two different zones, the burned and unburn zone. Each of them has its own mass. Hence the temperature is also different. The burned zone is assumed to be the temperature when the combustion happens, while the unburn zone is the temperature around the combustion chamber.

From the mass fraction value, the calculation of the two-zone combustion temperature can be done by adding an additional mix zone that act as the average temperature of both zone. 
Mix Zone:

Tmix $=\frac{\left(c_{\text {vburn }} \times m_{\text {burn }} \times T_{\text {burn }}\right)+\left(c_{\text {vunburn }} \times m_{\text {unburn }} \times T_{\text {unburn }}\right)}{\left(c_{\text {vburn }} \times m_{\text {burn }}\right)+\left(c_{\text {vunburn }} \times m_{\text {unburn }}\right)}$
The resulted temperature is illustrated by the figure below.

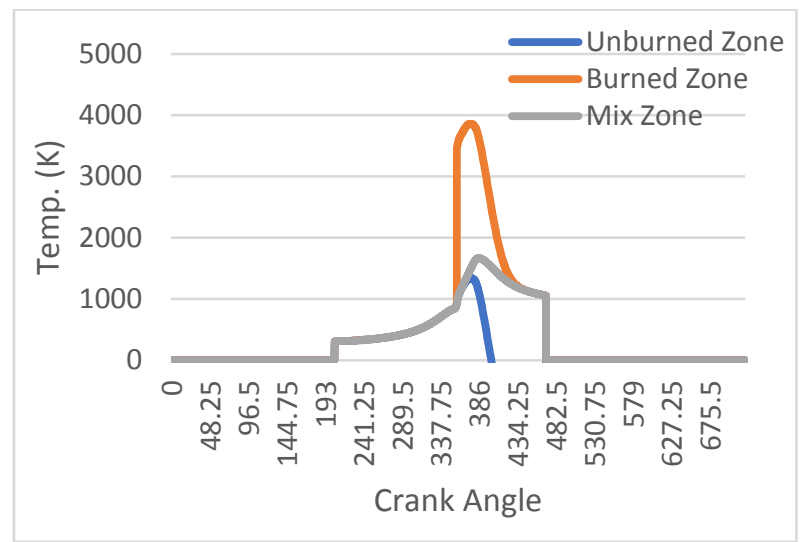

Figure. 5. Combustion Temperature

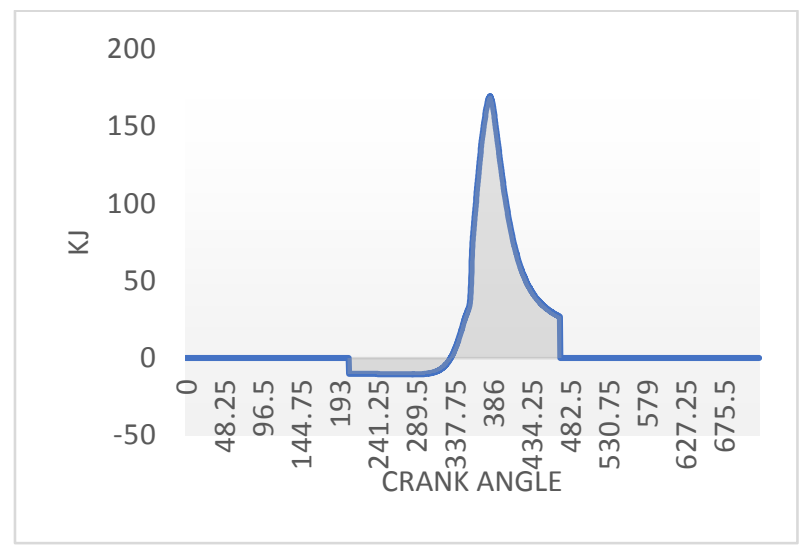

Figure. 6. Internal Energy

The graph shows an overview of combustion temperature from the unburned zone, burned zone and mix zone. All of the zone has the same trendline, where the temperature starts rising prior the TDC and gradually decrease for the power stroke. The blue graph represents the unburned temperature, where it starts rising at $205^{\circ}$ (intake valve closed) due to the effect of compression stroke. The temperature starts rising until it reached the $360^{\circ} \mathrm{CA}$ (TDC) and will gradually decreased due to the power stroke. Furthermore, the burned temperature which represent by the orange graph has the highest temperature around $3862 \mathrm{~K}$ at $376,75^{\circ}$ and at the same time the unburned temperature also reached its highest temperature with $1341 \mathrm{~K}$. After that, the outlet valve will open at $470^{\circ} \mathrm{CA}$ and the burned temperature have a value of $1060 \mathrm{~K}$ and the unburned temperature cannot be determined because the real value only last until $400^{\circ} \mathrm{CA}$. In addition, the green graph represents the mix zoned temperature.

\section{3) Internal Energy}

Basically, the internal energy is using the First Law of Thermodynamics as its idea. Where the energy cannot be destroyed but only can transform into different form. To calculate the internal energy, there are several parameters that have to be determined first. For example, the heat transfer $\left(Q_{w}\right)$, heat release $\left(Q_{f}\right)$ and mechanical work $(W)$.

The biggest parameter that affect the internal energy is the heat energy. And that explain why the trendline are almost the same as the heat transfer $\left(\mathrm{Q}_{\mathrm{w}}\right)$.

\section{B. External Chamber}

The idea of this secondary chamber is basically the same as the Volkswagen invention. However, this idea is designed for the $\mathrm{CI}$ engine and also the piston inside the secondary chamber will be drive by a spring. 


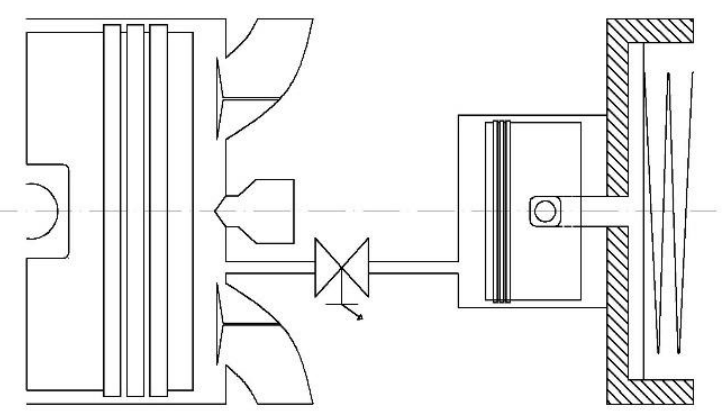

Figure. 7. External Chamber System
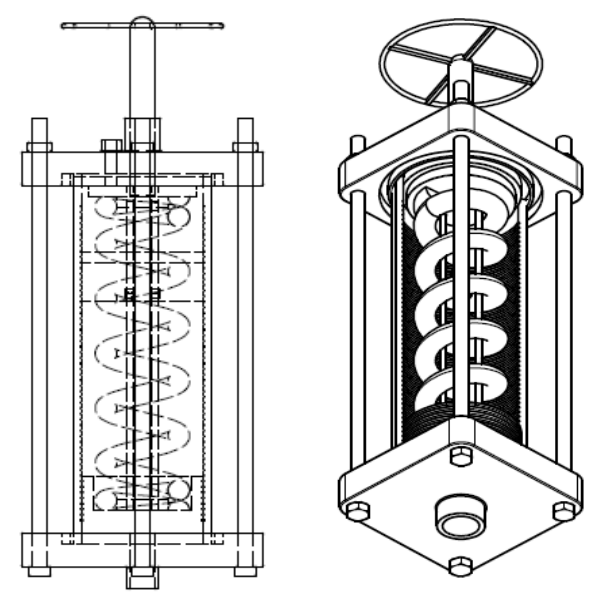

Figure. 8. External Chamber Design

The spring will deflect if the combustion pressure has exceeded the spring activation pressure, which allow the spring to deflect and created a bigger volume to store the energy from the combustion into the secondary chamber. When the pressure starts to decrease, the spring will start to expand and release the gas energy that was stored before. Hence, the purpose of this invention is to reduce the combustion temperature and keep the combustion pressure constant.
1) External Chamber Specification

The amount of energy and gas volume stored are depending on the volume of energy storage. So, determining the right piston bore and also the TDC volume of the chamber are very critical.

The deflection of the spring will be used as the stroke of the secondary chamber. There will be two spring that designed to handle each of their cylinder liner bore sizes and a stopper to adjust the spring maximum deflection

TABLE 3.

EXTERNAL CHAMBER SPECIFICATION

\begin{tabular}{llll}
\multicolumn{4}{c}{ EXTERNAL CHAMBER SPECIFICATION } \\
\hline Bore & 120 & 100 & $\mathrm{Mm}$ \\
Stroke & 5 & 10 & $\mathrm{Mm}$ \\
K Spring & 953.78 & 1898.28 & $\mathrm{~N} / \mathrm{mm}$ \\
Activation Pressure & 70 & 70 & $\mathrm{Bar}$ \\
Activation Force & 79168.1 & 54977.9 & $\mathrm{~N}$ \\
Material & \multicolumn{4}{c}{ Ceramic and Aluminum Alloy } \\
\hline
\end{tabular}




\section{2) Energy Stored}

The energy inside the secondary chamber will be calculated using the First Thermodynamic Law. Where the internal energy interchange will happen if the spring have start deflecting.

\section{Internal energy stored:}

$\frac{d U}{d \varphi}=\left(\frac{d Q 1}{d \varphi}-\frac{d W 1}{d \varphi}\right)-\left(\frac{d Q 2}{d \varphi}-\frac{d W 2}{d \varphi}\right)$

According to the equation above there are two parameters that has to be determined, the spring work and the secondary chamber heat energy. The deflection has a major influence to the spring work. As the spring work equation is.

\section{Spring Work:}

$W_{\text {spring }}=\frac{k x \delta^{2}}{2}$

The next step is to simulate the spring work based on the crank angle. Each of crank angles has its own cylinder pressure value. Therefore, when the spring starts to deflect, it will store the work energy from the combustion and will release it if the pressure has start to decrease. Since the stopper is set for a $10 \mathrm{~mm}$ deflection, hence deflection beyond that value is impossible.

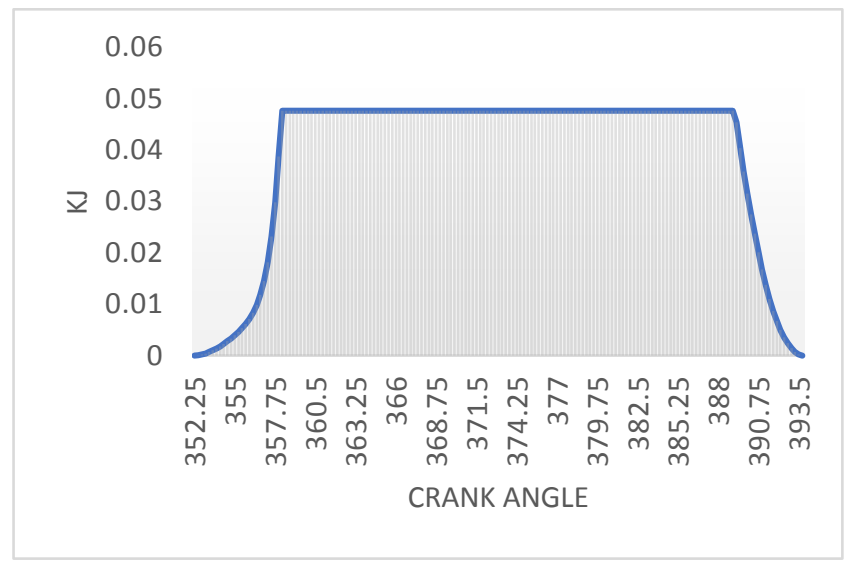

Figure. 9. Spring Work

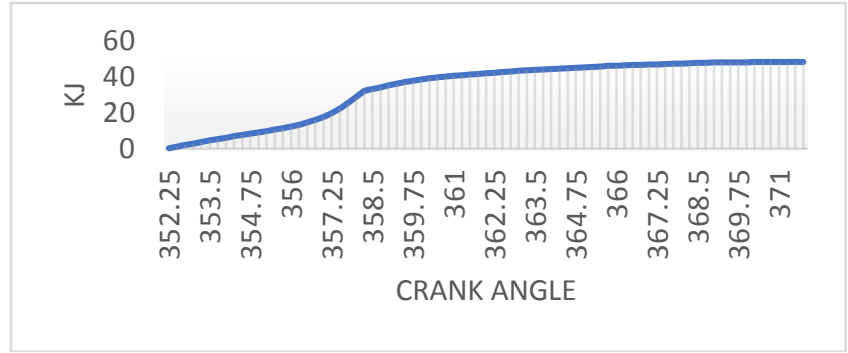

Figure. 10. Internal Energy Stored

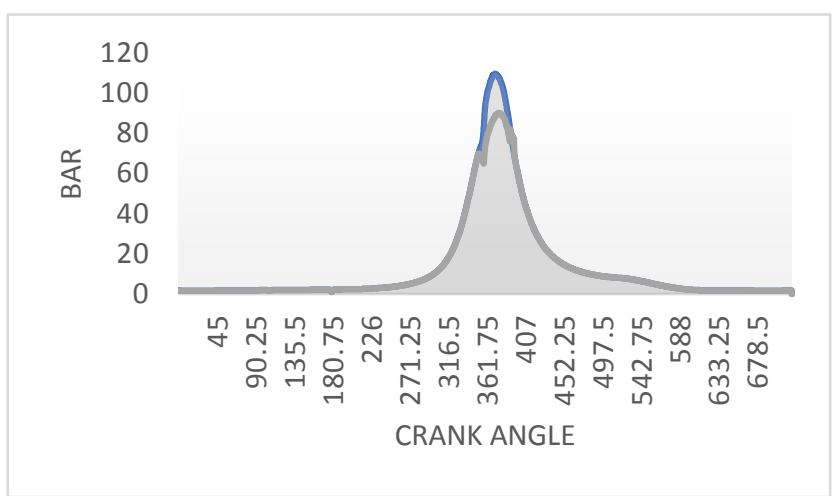

Figure. 11. New Cylinder Pressure

From the graph can be seen that the spring started to deflect at $352.25^{\circ} \mathrm{CA}$ due to the cylinder pressure have exceeded the spring activation pressure. Then at $371.75^{\circ}$, it is the point where the spring have the highest amount of force as it's correlated with the cylinder pressure. And at $393.5^{\circ}$, the spring has released its last work energy 
since the cylinder pressure has decreased lower than the activation pressure.

From the graph can be seen that at $352.25^{\circ}$ C.A, the internal energy stored started to rise gradually due to the cylinder pressure exceeded the activation pressure. The value keeps rising until $371.75^{\circ}$ C.A, where the amount of the internal energy stored reached its maximum point with $91.9 \mathrm{~kJ}$. After that, the internal energy stored will be released into the combustion chamber.

\section{3) Effect of the External Chamber}

Due to the installation of the secondary chamber into the engine, there is a changing to the cylinder pressure. As the secondary chamber can stored the energy and release it later, there will be a new pressure calculation that can be seen in the equation below.

\section{New Cylinder Pressure:}

$P=\frac{2 x \Delta U_{\text {secondary chamber }}}{\frac{\pi}{4} \times \text { bore }^{2} x \delta}$

The new cylinder pressure will have a reduced peak pressure which resulted from the secondary chamber. The graph down below illustrates the comparison between the old cylinder pressure and the new cylinder pressure.

From the graph can be seen that at $352.25^{\circ} \mathrm{CA}$, the cylinder pressure began to have a constant value due to the opening of secondary chamber valve until it reached $371.75^{\circ} \mathrm{CA}$. Where the internal energy that has been stored will be released into the main combustion chamber until $393.75^{\circ}$ C.A.

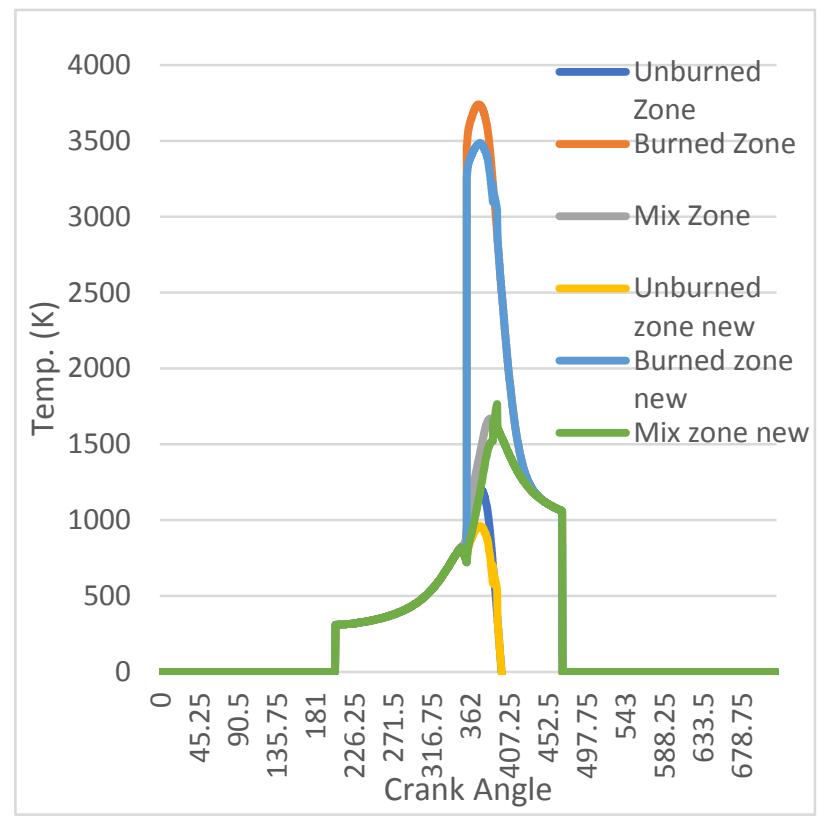

Figure. 12. Temperature Comparison

TABLE 4.

PEAK TEMPERATURE COMPARISON

\begin{tabular}{lrrr}
\hline Zone & Conventional [K] & New [K] & Reduced \\
\hline Burn & 3853 & 3616 & $6.15 \%$ \\
Unburn & 1332 & 1094.5 & $17.80 \%$ \\
\hline
\end{tabular}

From the graph above can be seen that there is slight difference in the peak temperature, where at $376.75^{\circ} \mathrm{CA}$ the conventional burned had the highest temperature with $3853 \mathrm{~K}$. While the modified burned temperature had its highest temperature at $377,75^{\circ}$ with $3616 \mathrm{~K}$. In conclusion, the modified burned peak temperature has a smaller value around $6.15 \%$ from the conventional temperature.

There is a significant difference on the peak temperature, where the conventional unburned temperature had a value of $1332 \mathrm{~K}$ at $376,75^{\circ} \mathrm{CA}$ and the modified unburned temperature had $1094,5 \mathrm{~K}$ at $377,75^{\circ}$ CA. The difference between them is $17,8 \%$, that is a big difference and shows that the secondary chamber proves can reduce the combustion temperature effectively.

\section{CONCLUSION}

Based on the simulation results, there are several points that can be concluded:

1. There are several parameters that are imperative to the calculation of the energy stored for example, compression pressure and the crank angle position when the combustion starts and the heat transfer.

2. The peak cylinder pressure is reduced since the external chamber stored some of the energy from the combustion process. 
3. By installing the external chamber, based on the calculation, the peak burned and unburned temperature could be reduced by $6.15 \%$ and $17.8 \%$ respectively, compared to the stock engine. Furthermore, according to the temperature graph a constant temperature combustion could be achieved since the equipment restored the energy that has been stored.

\section{REFERENCES}

[1]. Wahl, A.M., 1944. Mechanical Spring. The Penton Publishing Company, Cleveland, Ohio.

[2]. Spotts, M.F., 1985. Design of Machine Elements. Prentice-Hall of India Private Limited, New Delhi.

[3]. Rao, S., 1996. Engineering Optimization: Theory and Practice. 3rd Edn., John Wiley and Sons, New York, ISBN: 0-471-55034-5, pp:858-864.

[4]. Fathallah, A.Z.., Bakar, R.., 2010. The Effect of Spring Design as Return Cycle of Two Stroke Spark Ignition Linear Engine on the Combustion Process and Performance. American J. of Engineering and Applied Sciences 3.

[5]. Ristiawan, A., Soeprajitno, T., Fathallah, A.Z.., 2013. Desain Pegas pada Motor Bakar Gerak Linier Bersilinder Tunggal dengan Menggunakan Solver. JURNAL TEKNIK SISTEM PERKAPALAN 04.

[6]. Hebbar, G.S., 2014. NOx from Diesel Engine Emission and Control Strategies - A Review. International Journal of Mechanical Engineering and Robotics Research.

[7]. Fathallah, A.Z.., Semin, Ariana, I.., Gerianto, I., 2014. Motions Study of a Single Cylinder High Speed Spark Ignition Linier Engine with Spring System as Return Cycle. American J. of Engineering and Applied Sciences.

[8]. Prawira, G., 2018. Development of a Computer Based Combustion Process of a 4 Stroke Diesel Engine and Calculation of Exhaust Gas Emissions for Different Conditions. Hochschule Wismar, Rostock. 